\title{
Health Education Materials for the Workplace: Implementation guide for workplaces
}

David Wofford

Suzanne Brockman

Carolyn Rodehau

Follow this and additional works at: https://knowledgecommons.popcouncil.org/departments_sbsr-rh How does access to this work benefit you? Let us know!

\section{Recommended Citation}

Wofford, David, Suzanne Brockman and Carolyn Rodehau. 2018. "Health Education Materials for the Workplace: Implementation guide for workplaces." Washington, DC: Population Council, The Evidence Project. 


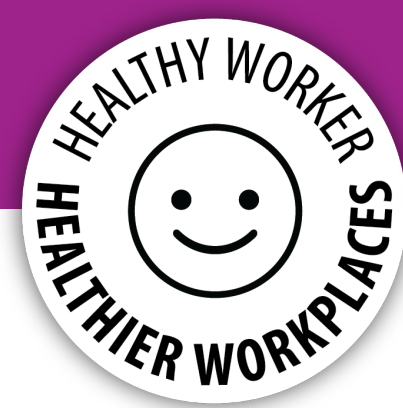

\title{
Health Education Materials for the Workplace
}

\section{IMPLEMENTATION GUIDE FOR WORKPLACES}

\author{
January 2018
}




\section{ACKNOWLEDGMENTS}

This guide is a supplement to a set of Health Education Materials designed for workplaces in low- and middle-income countries. It is intended to suggest ideas and good practices for using the materials as part of workplace health promotion.

This guide was developed by David Wofford, Suzanne Brockman, and Carolyn Rodehau of the Evidence Project/Meridian Group International, Inc., in partnership with Bayer, led by Ulrich Madeja, MD. It was first used in Bangladesh by the Better Work Program of the International Labor Organization and the International Finance Corporation, in a training program in October 2018 with five factories on how to use the health education materials. Special thanks to Maruf Hassan Khan of Better Work Bangladesh and Meridian's local consultant, Ahmed Mollah Mahmud, an information, education, and communication and training expert.

The Health Education Materials were developed through an initial partnership formed between Bayer and the Evidence Project/RAISE Health to design family planning and reproductive health materials in collaboration with HERproject, the workplace health education initiative of Business for Social Responsibility. Marat Yu, Lauren Shields, and Maria Pontes of Business for Social Responsibility also contributed to conceptualizing and reviewing these resources. The Bengali versions of the Health Education Materials were formally approved by the Bangladesh Ministry of Health and contains the ministry's logo as well as those of partner organizations in Bangladesh.

The materials were designed by Atelier Hauer+Dörfler Kreativagentur, a Germany-based design firm. Many thanks as well go to Kate Giles and Anneka Van Scoyoc of the Evidence Project for their edits, ideas, and communications expertise in the development of the materials and the Implementation Guide.

Collaboration with other health projects and NGOs was a key feature in the development process, in order to expand the suite of materials to reflect a more comprehensive range of health topics. We identified and reviewed materials from a wide range of health NGOs using the K4Health website and other health websites. Key messages are based on existing health information or educational materials and incorporate in-country and government messages produced by:

- USAID and its cooperating agencies (global projects)

- UNICEF

- World Health Organization

- Business for Social Responsibility HERproject

- WaterAid

- Global Handwashing Day

- Alive and Thrive

- Nutrition Working Group of CORE Group

- MenEngage/Promundo

_ Interagency Gender Working Group

Further input into content development was also received from Kate Doyle (Promundo) as well as BSR HERproject implementing organizations in Bangladesh (Change Associates and Mamata) and Kenya (National Organization of Peer Educators). 


\section{INTRODUCTION}

This Implementation Guide provides ideas for how you can use the Health Education Materials at your place of work. These materials cover five important health topic for workers:

- Hand Washing

- Menstrual Hygiene

- Healthy Timing and Spacing of Pregnancy

- Family Planning Methods

- Engaged Fathers and Health

\section{THE PURPOSE OF THE HEALTH EDUCATION MATERIALS}

These materials are tools to support your efforts to improve the health of workers. There are 3 things to know about the materials:

$\rightarrow \quad$ They are meant to give very simple messages. Why?

Because the goal is to reinforce basic information in your trainings and health education activities. Also, the goal is to encourage workers to get more detailed information and guidance from doctors, nurses and other qualified health workers.

$\rightarrow \quad$ They are meant to look simple. Why?

Because they have been designed to be printed at your workplace on desktop printers. Materials with lots of colors, photos and drawings do not print out clearly. So there is a simple color version and a simple black and white version for each topic.

$\rightarrow \quad$ They are meant to available whenever you need them. How?

These materials will be on the workplace computers as electronic files and available from websites as well. This way, they will always be available when you need them. You will never run out of materials - because you can always print more. And you can print just the number you need at any time.

\section{THE USERS OF THE MATERIALS}

The primary audience for the materials are women and men workers. But certain employees will use the materials the most in their work. Who? Anyone who plays one of these roles at the workplace:

- Nurses

- Welfare Officers or Safety Staff

- Paramedics or Health Assistants

- Peer educators

These people will also find these materials useful and play important roles, including:

- Managers or supervisors with responsibility for human resources, compliance or other health and safety areas - and can ensure access to printers or copies.

- Doctors who oversee or work in the workplace infirmary 


\section{THE MAIN WAYS TO USE HEALTH EDUCATION MATERIALS}

You can use the materials in many different ways depending on your needs. These materials come in three types:

- Handouts - with more information

- Mini (small) Posters - with a little less information, and

- Question \& Answer (Q\&A) supplements - for more participatory ways to provide information.

The main difference between each type of material is the amount of information on each. Any of them can be handed out or posted or used in participatory health trainings.

These are some of the main ways to use the materials:

\section{$\rightarrow$ As a Job Aid}

If you are counseling or training workers, you can use the materials as a reference tool to make sure you have mentioned all the key messages.

You can keep these in a desk or in a pocket or posted on the walls of the infirmary, health station or office. That way you can refer to the key health messages anytime.

The health education materials may be most helpful when you have one-to-one counseling sessions with a worker. The materials can refresh your knowledge of certain topics, such as family planning.

For instance, one handout of the various methods can be used as a counseling tool for helping workers choose the best family planning method for them. These materials can help build confidence and ability to answer sensitive questions on many different health topics.

\section{$\rightarrow$ As Tools to Support for Your Health Trainings}

It is best to give these materials as handouts to workers after you have given a training or done counseling. They are meant to reinforce the new information they have learned.

The Question and Answer supplements also give you a way to check to see if workers have understood or remembered the key messages and information after the training.

When should you use the handouts?

- After one-on-one counseling. The materials help a worker remember the key message during the meeting with a nurse or doctor.

- During and after peer education. The handouts can help worker peer educators give accurate health messages to their co-workers. This also allows workers to take the information home to read in private - as well as to share with friends, families and peers.

- During health trainings. Often the best way to communicate health messages is to make the information fun through games and questions. That's why the Question and Answer supplement handouts are in the form of quizzes that you can use with workers in fun ways.

A common participatory technique for training a large group of workers is to divide the workers into two or three smaller groups. Each group answers the questions separately. Then you have a competition to see which group answered the most right. This then allows you to have a discussion about those questions that were not answered right.

Some workplaces have also used the Question and Answer supplements or messages from the other handouts as quizzes that they ask over the public address systems relating to the "message of the week." Some even give small prizes to the workers or lines that get the answer right. 


\section{$\rightarrow \quad$ As a Way to Reach Large Numbers of Workers}

The Mini Posters, having the least information, are a way to give basic health messages to large numbers of workers by putting them in public spaces, as appropriate. These are some suggested places to post them:

$\begin{array}{lll}\text { Infirmary waiting room } & \text { Human Resources office } & \text { Security stations } \\ \text { Clock-in Station } & \text { Commissary } & \text { Training rooms } \\ \text { Restrooms } & \text { Water station } & \text { Infirmary wall } \\ \text { Bulletin Boards } & \text { Hand washing stations } & \text { Cafeteria } \\ \text { Daycare center } & \text { Bus depots } & \end{array}$

You should place the more sensitive health topics only in areas that are acceptable. These posters can be replaced whenever they get old by printing new ones. It makes most sense to print the Mini-Posters in color, if possible, to make them more visible.

\section{$\rightarrow$ As a component of our health-related activities}

Workplaces have many health-related activities when you can share the health education materials, including:

- The orientation of new nurses. When new nurses are hired they have an orientation to their new job duties. A training on the Health Education Materials can be a part of the orientation.

- The Health and Safety component of orientation for new workers. New worker orientation is a great time to provide the health education messages.

- Health fairs or occupational health and safety (OHS) trainings. You can use the Health Education materials during these events to give workers information on important health issues.

Once you start working with these materials, you will find other good times to use them.

\section{THE MANAGEMENT OF THE HEALTH EDUCATION MATERIALS}

The workplace needs to make sure the Health Education materials are available for the health team and others to use. This requires three actions:

$\rightarrow \quad$ Getting Management Approval. Management needs to approve the use of workplace computers and printers for reproducing the materials. The electronic files will be kept on a designated computer in a designated office. The staff of the office need to understand that printing the materials is an approved use of the equipment.

$\rightarrow$ Ensuring Access to Computers and Printers. The health teams must be given access to the computer and printer. This equipment will often be needed for business activities. So management needs to create a clear process for when the health team or responsible persons can have copies of the materials made.

$\rightarrow$ Assigning Responsibility. Someone needs to be assigned responsibility for the Health Education materials. That person or persons is in charge of:

- Ensuring the health team and other staff use the materials.

- Ensuring there is adequate supplies of materials as needed for education or training sessions, counseling and peer education.

- Replacing posters that have become old.

- Working with the designated office or manager, according to the agreed upon process, to reproduce the materials.

The likely responsible persons will be nurses or welfare offices - but it can be anyone involved in worker health and safety or in human resources. 
You should consider several other issues in managing the health education materials:

- Keep a very small supply of each material somewhere, likely in the infirmary, so a few are always available.

- Print only the number of materials you will need for a training and your small supply - so you do not waste paper or factory resources.

- Use the electronic version when you make a first copy of the materials - and frequently after that. This keeps the materials looking sharp. If you make photocopies of photocopies, the materials will start looking blurry and dull.

- Remember to use the Black \& White electronic files for printing the materials in black and white. These will look better than using the color files on a black and white printer.

- Consider using printing the Mini-Posters in color to make them stand out. You will likely print most of the materials in black and white to save on cost.

WHERE TO FIND THE MATERIALS

\section{The Evidence Project}

http://evidenceproject.popcouncil.org/resource/health-education-materials-for-the-workplace/

\section{Bayer}

www.your-life.com/workplace

$\rightarrow \quad$ The Bayer website also has health education materials on nutrition.

$\rightarrow$ You can check these websites in the future for upcoming additional languages, including Arabic, Spanish and Swahili.

$\rightarrow$ Please note that the content of the translated materials will contain small differences from the English versions based on national messages and cultural sensitivities. These differences, however, do not change the primary content or messages of the originals. 


\section{APPENDIX: LIST OF HEALTH EDUCATION MATERIALS}

\begin{tabular}{|c|c|c|c|}
\hline \multicolumn{4}{|l|}{ HAND WASHING } \\
\hline \multicolumn{4}{|c|}{ 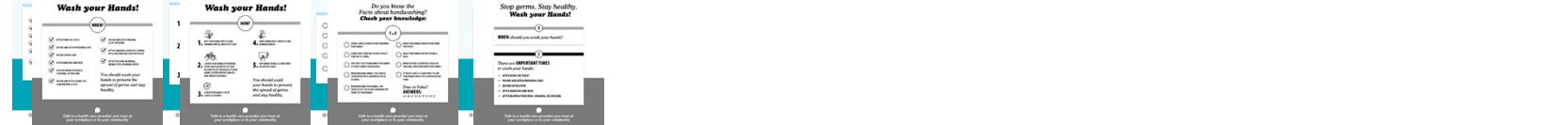 } \\
\hline TYPE OF MATERIAL & MESSAGES & & SUGGESTED USES OF MATERIAL \\
\hline Handout 01 & When to wash your hands & $\Rightarrow$ & As a job aid to help you talk to workers \\
\hline Handout 02 & How to wash your hands & $\Rightarrow$ & As a handout for health trainings \\
\hline \multirow[t]{2}{*}{ Q\&A Supplement } & When should you wash your hands? & $\Rightarrow$ & As a job aid to test workers knowledge \\
\hline & These are the important times... & $\Rightarrow$ & $\begin{array}{l}\text { As a fun game or competition on family } \\
\text { planning knowledge with groups of } \\
\text { workers }\end{array}$ \\
\hline \multirow[t]{2}{*}{ Mini-Poster 01} & $\begin{array}{l}\text { Stop germs. Stay Healthy. Wash your } \\
\text { hands. }\end{array}$ & $\Rightarrow$ & $\begin{array}{l}\text { Place on rest room walls, bulletin boards, } \\
\text { public spaces etc. }\end{array}$ \\
\hline & & $\Rightarrow$ & Use to reach large numbers of workers \\
\hline
\end{tabular}

\section{FAMILY PLANNING}

\section{$\rightarrow 4$ MATERIALS}
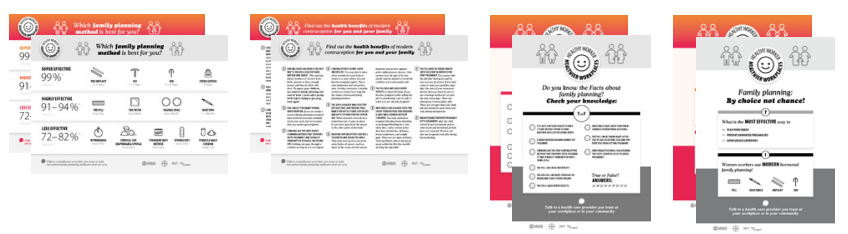

\begin{tabular}{|c|c|c|}
\hline TYPE OF MATERIAL & MESSAGES & SUGGESTED USES OF MATERIAL \\
\hline Handout 01 & $\begin{array}{l}\text { Which family planning method is best } \\
\text { for you? }\end{array}$ & \multirow{2}{*}{$\begin{array}{l}\rightarrow \quad \text { As a job aid to help you talk to workers } \\
\rightarrow \quad \text { As a handout for workplace health } \\
\text { trainings } \\
\rightarrow \quad \text { As a handout for one-on-one counseling } \\
\text { with a worker }\end{array}$} \\
\hline Handout 02 & $\begin{array}{l}\text { Find out the health benefits of modern } \\
\text { contraception for you and your family. }\end{array}$ & \\
\hline Q\&A Supple-ment & $\begin{array}{l}\text { Do you know the facts about family } \\
\text { planning? Test your knowledge. }\end{array}$ & $\begin{array}{l}\rightarrow \quad \begin{array}{l}\text { As a job aid to test workers' knowledge } \\
\text { before or after training }\end{array} \\
\rightarrow \quad \begin{array}{l}\text { As a fun game/ competition on family } \\
\text { planning knowledge with groups of } \\
\text { workers }\end{array} \\
\end{array}$ \\
\hline Mini-Poster 01 & Family Planning: By Choice, Not Chance! & $\begin{array}{l}\rightarrow \quad \text { Place on clinic walls and any other } \\
\text { acceptable spaces such as the women's } \\
\text { restroom }\end{array}$ \\
\hline
\end{tabular}




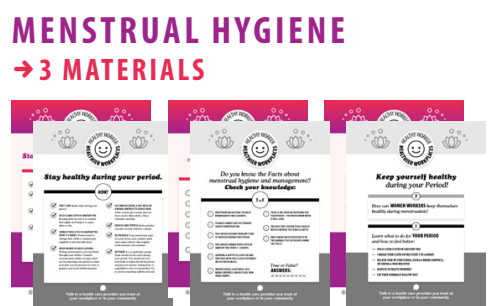

TYPE OF MATERIAL

\section{MESSAGES}

SUGGESTED USES OF MATERIAL

Handout 01

How to stay healthy during your period

$\rightarrow$ As a job aid to help you talk to workers

$\rightarrow$ As a handout for workplace health trainings

\section{Q\&A Supplement} Do you know the facts about menstrual hygiene management?

$\rightarrow$ As a fun game or competition to test family planning knowledge with groups of workers

\begin{tabular}{ll}
\hline Mini-Poster 01 & $\begin{array}{l}\text { Keep yourself healthy during your } \\
\text { period. }\end{array}$
\end{tabular}

$\rightarrow \quad$ Place on clinic walls and any other acceptable spaces such as the women's restroom

\section{HEALTHY TIMING AND SPACING OF PREGNANCY}

\section{$\rightarrow 2$ MATERIALS}

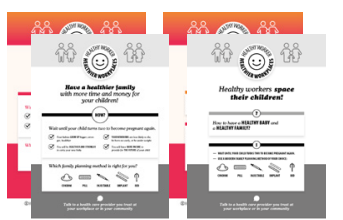

\section{TYPE OF MATERIAL}

\author{
Handout 01
}

\section{MESSAGES}

Have a healthier family with more time and money for your children! How?

\section{SUGGESTED USES OF MATERIAL}

$\rightarrow \quad$ As a job aid to help you talk to workers about how to space children and why

$\Rightarrow \quad$ As a handout for workplace health trainings

\section{Mini-Poster 01}

$\rightarrow$
Place on clinic walls and any other acceptable spaces such as the women's restroom 
ENGAGED FATHERS \& HEALTH

$\rightarrow 3$ MATERIALS

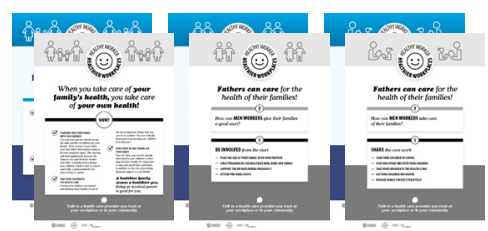

TYPE OF MATERIAL

Handout 01

When you take care of your family's health, you take care of your own health! acceptable spaces such as the women's restroom

Mini-Poster $01 \quad$ Fathers can care for the health of their families! How can men workers give their families a good start?

$\rightarrow \quad$ As a job aid to help you talk to workers

$\rightarrow \quad$ As a handout for workplace health trainings

Mini-Poster 02 Fathers can care for the health of their families! How can men workers take

$\rightarrow$ Place on rest room walls, bulletin boards, care of their families? public spaces, etc.

$\rightarrow \quad$ Use to reach large numbers of men workers (but women too). 


\section{The Evidence Project}

Population Council

4301 Connecticut Avenue, NW, Suite 280

Washington, DC 20008 USA

tel +12022379400

evidenceproject.popcouncil.org

\section{(2) USAID}

The Evidence Project is made possible by the generous support of the American people through the United States Agency for International Development (USAID) under the terms of cooperative agreement no. AID-OAA-A-13-00087. The contents of this document are the sole responsibility of the Evidence Project and Population Council and do not necessarily reflect the views of USAID or the United States Government.

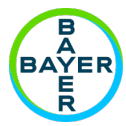

Bayer is a global enterprise with core competencies in the Life Science fields of health care and agriculture. Its products and services are designed to benefit people and improve their quality of life. At the same time, the Group aims to create value through innovation, growth and high earning power. Bayer is committed to the principles of sustainable development and to its social and ethical responsibilities as a corporate citizen.

\section{Evidence}

The Evidence Project uses implementation science - the strategic generation, translation, and use of evidence-to strengthen and scale up family planning and reproductive health programs to reduce unintended pregnancies worldwide. The Evidence Project is led by the Population Council in partnership with INDEPTH Network, International Planned Parenthood Federation, PATH, Population Reference Bureau, and a University Research Network.

\section{Meridion Grour International, Inc.}

Meridian Group International, Inc. is a woman-owned, small business that works with the private and public sectors to create innovative programs and partnerships that benefit both business and society. RAISE Health is a major activity of the USAID-funded Evidence Project. Implemented by Meridian Group International, Inc., an Evidence Project partner, RAISE Health combines implementation science with its extensive experience implementing workplace health programs and promoting better policies and practices within the global framework of codes and compliance.

Published in January 2018.

Suggested citation: David Wofford, Suzanne Brockman and Carolyn Rodehau. 2018. Health Education Materials for the Workplace: Implementatoin Guide, Guidance Document. Washington, DC: Population Council, The Evidence Project.

(c) 2018 The Population Council, Inc. 